\title{
Avaliação da deposição pulmonar da dexametasona quando administrada por via inalatória em equinos
}

Ayrton Rodrigo Hilgert, Vagner Gonçalves, Guilherme de la Penha Fernandes, Tiago Marcelo Oliveira, Talissa r Martins, Paulo

Moreira Bogossian, Cristina Oliveira Massoco, Wilson Roberto Fernandes

Universidade de São Paulo (USP), São Paulo, SP, Brasil

*Autor correspondente

e-mail: ayrton.hilgert@gmail.com

\section{Resumo}

Afecções do sistema respiratório estão entre as mais frequentes em equinos, sendo a segunda maior causa de baixo desempenho no cavalo atleta. Dentre essas doenças, pode-se citar as afecções puramente inflamatórias das vias aéreas, conhecidas como Doenças Inflamatória das Vias aéreas (DIVA) e Obstrução Recorrente das Vias Aéreas (ORVA), que apresentam prevalência considerável e afetam a saúde e vida atlética do animal. Um dos principais meios de atuação terapêutica no tratamento dessas doenças é a administração de medicamentos antiinflamatórios corticosteroides, sendo a dexametasona um dos mais relevantes fármacos dessa classe utilizados na medicina equina. No tratamento de doenças semelhantes em humanos, preconiza-se a administração dos fármacos por via inalatória, otimizando de maneira significativa o seu efeito terapêutico e diminuindo os efeitos colaterais. Em equinos, existem trabalhos que mostram a deposição pulmonar e o efeito benéfico de medicamentos quando administrados por via inalatória, no entanto não foram encontrados estudos nesse sentido utilizando a dexametasona. 0 objetivo desse estudo foi avaliar a deposição pulmonar de dexametasona quando administrada por meio de nebulização pneumática em equinos, bem como fatores que possam interferir no seu nível de deposição e a concentração plasmática do fármaco quando administrada por essa via. Para isso foram utilizados seis equinos submetidos duas vezes à inalação (nebulizador pneumático e máscara facial do tipo Aeromask ${ }^{\circledR}$ ) com dexametasona, cada vez utilizando um veículo diferente (aquoso ou oleoso) na formulação do fármaco. Quatro animais foram utilizados para o grupo controle, sendo submetidos à inalação somente com os veículos. Após cada inalação foi realizado um lavado broncoalveolar (LBA) e coletas sanguíneas seriadas, todos analisados pela técnica de Cromatografia Líquida de Alta Performance (HPLC) para quantificação da dexametasona. 0 fármaco administrado foi identificado nas amostras de LBA dos animais dos grupos tratados (sem apresentar diferença significativa entre os diferentes veículos) e não foi identificado no plasma de nenhum animal. 
Esses resultados nos sugerem que essa via de administração de dexametasona pode ser segura, uma vez que a concentração plasmática se manteve abaixo do limite de detecção da técnica $(0,78 \mu \mathrm{g} / \mathrm{ml})$. Além disso, pela sua já conhecida ação local no combate à inflamação, podemos inferir que ao atingir as vias aéreas inferiores a dexametasona possivelmente exercerá um efeito antiinflamatório nessa região. No entanto, são necessários mais estudos para que essa hipótese seja validada. Desta forma, o presente trabalho conclui que a dexametasona, quando administrada via nebulização pneumática, atinge a região de bronquíolos e alvéolos respiratórios em equinos, possibilitando a sua ação nessa região.

Palavras-chave: Nebulização. Glicocorticóides. Lavado broncoalveolar. 